\title{
O LABOR NANOTECH E A NECESSÁRIA METAMORFOSE JURIDICA: Como as Atuais Sociedades de Risco Podem se Valer de um Ambiente Regulatório Pluralista para a Garantia do Não Retrocesso à Dignidade Humana do Trabalhador ${ }^{1}$
}

http://dx.doi.org/10.21527/2176-6622.2021.56.10312

Recebido em: 5/3/2020

Aceito em: 19/4/2021

Wilson Engelmann

Universidade do Vale do Rio dos Sinos (Unisinos).

Raquel von Hohendorff Universidade do Vale do Rio dos Sinos (Unisinos).

Isabelle de Cássia Mendonça

Autora correspondente. Universidade do Vale do Rio dos Sinos (Unisinos). Av. Unisinos, 950 - Cristo Rei. São Leopoldo/RS, Brasil. CEP 93022-750. http://lattes.cnpq.br/9736144655399384. https://orcid.org/0000-0002-3052-824X. isabelledecassiamendonca@hotmail.com

\section{RESUMO}

A evolução tecnocientífica pós-modernista conquistou níveis moleculares de manipulação. Tal constatação é verificada com o advento da "Revolução Nanotecnológica", isto é, a interação e a produção de nanopartículas - estas correspondentes à bilionésima parte do metro. Dessa maneira, indubitavelmente, o campo laboral faz-se alvo dessa inovação que cresce consideravelmente - e sem qualquer certeza quanto às consequências da interação nano com os seres vivos. Surgem, por conseguinte, preocupações no campo jurídico-trabalhista, principalmente na falta de marcos regulatórios específicos. O objeto do presente estudo, portanto, está na demonstração da importância da atuação de diferentes atores para a proteção da dignidade humana do trabalhador, isto é, a esfera governamental e a esfera particular, diante da inércia do Poder Legislativo. Para tanto, o método utilizado foi o sistêmico-construtivista, assim como revisões bibliográficas, por meio de pesquisa de bases que não compõem o Direito tradicional. Assim, a harmonização de diferentes polos faz-se de suma importância, uma vez que se considera a necessidade do não retrocesso na dignidade humana dos trabalhadores. Ademais, fontes formais e informais atuando, conjuntamente, estão a se consolidar, principalmente diante de uma sociedade de risco e que se caracteriza pelo caráter líquido dos conceitos clássicos - em especial, o próprio Direito (objeto de análise).

Palavras-chave: Nanotecnologias; direito do trabalho; princípio do não retrocesso; pluralismo jurídico; dignidade humana.

THE NANOTECHNOLOGICAL WORK AND THE NECESSARY LEGAL METAMORPHOSIS: HOW CURRENT RISK SOCIETIES CAN USE

A PLURALISTIC REGULATORY ENVIRONMENT TO ENSURE THAT THE WORKER DOES NOT FALL BACK ON HUMAN DIGNITY

ABSTRACT

Postmodernist techno-scientific evolution has achieved molecular levels of manipulation. Such finding is verified with the advent of the "Nanotechnological Revolution", that is, the interaction and the production of nanoparticles - these corresponding to the billionth part of the meter. In this way, undoubtedly, the labor field becomes the target of this innovation that grows considerably - and without any certainty as to the consequences of the nano interaction with living beings. Consequently, concerns arise in the legal-labor field, mainly in the absence of specific regulatory frameworks. Therefore, the object of the present study is to demonstrate the importance of the performance of different actors for the protection of the human dignity of the worker, that is, the governmental sphere and the private sphere, in the face of the inertia of the Legislative Power. For that, the method used was the systemic-constructivist, as well as bibliographic reviews, through research of bases that do not compose the traditional Law. Thus, the harmonization of different poles is of paramount importance, since the need for non-retrogression in the human dignity of workers is considered. Also, formal and informal sources acting together are consolidating, mainly, in the face of a risk society that is characterized by the liquid nature of classic concepts - in particular, the Law itself (object of analysis).

Keywords: Nanotechnologies; labor law; principle of non-setback; legal pluralism; human dignity.

\footnotetext{
Este trabalho é o resultado parcial das pesquisas realizadas pelos autores no âmbito dos seguintes projetos de pesquisa: a) Edital 02/2017 - Pesquisador Gaúcho - PqG: Título do Projeto: "A autorregulação da destinação final dos resíduos nanotecnológicos", com apoio financeiro concedido pela Fundação de Amparo à Pesquisa no Estado do Rio Grande do Sul - Fapergs; b) Chamada MCTIC/CNPq № 28/2018 - Universal/Faixa C, projeto intitulado: "Nanotecnologias e Direitos Humanos observados a partir dos riscos no panorama da comunicação entre o Ambiente Regulatório e o Sistema da Ciência"; c) "Sistema do Direito, novas tecnologias, globalização e o constitucionalismo contemporâneo: desafios e perspectivas", Edital Fapergs/Capes 06/2018 - Programa de Internacionalização da Pós-Graduação no RS; d) "Transdisciplinaridade e Direito: construindo alternativas jurídicas para os desafios trazidos pelas novas tecnologias", com apoio financeiro concedido pela Fundação de Amparo à Pesquisa no Estado do Rio Grande do Sul - Fapergs - Edital 04/2019, Auxílio Recém-Doutor. Ademais, o presente trabalho foi desenvolvido no âmbito do Grupo de Pesquisa Jusnano (www.jusnano.blogspot.com - instagram: @jusnano.unisinos - facebook: /JusNanoUnisinos).
} 
O LABOR NANOTECH E A NECESSÁRIA METAMORFOSE JURÍDICA: COMO AS ATUAIS SOCIEDADES DE RISCO PODEM SE VALER DE UM AMBIENTE REGULATÓRIO PLURALISTA PARA A GARANTIA DO NÃO RETROCESSO À DIGNIDADE HUMANA DO TRABALHADOR Wilson Engelmann - Raquel von Hohendorff - Isabelle de Cássia Mendonça

\section{1 ÁTRIO²}

Eis a recepção de um novo mundo.

Quando os gregos poderiam imaginar que o pátio central do desenvolvimento humano iria além dos átomos de Leucipo e Demócrito? Nas últimas décadas a humanidade reformou, construiu e reconstruiu a recepção do conhecimento - já não se faz, nem ao menos incognoscível, a manipulação molecular. Não é em vão que, recorrendo às figuras pós-modernistas, Bauman (2001) compreende que estamos diante de um mundo liquefeito. Nada é para durar. O mundo se faz fluído e volátil. Os átrios bombeiam em uma frequência incontrolável.

O novo mundo deságua em uma "Revolução Nanotecnológica". Assim como a queda de Constantinopla marcou o fim da Idade Média e o início da "Era Renascentista", o advento da nanotecnologia, em meados da década de 50 do século 20, propôs um marco para uma nova "Era" na história da humanidade tecnocientífica. A conquista do "Império molecular", a interação e a produção de nanopartículas nos laboratórios mundiais, revolucionou (e revoluciona) a vida humana e os diferentes campos do conhecimento - destacadamente, como aqui será trabalhado, o campo do Direito.

Tamanha apresenta-se a expansão do mercado nanotecnológico global, que os números estão para exceder a marca de US\$ 125 bilhões em 2024 (GLOBAL, 2018), o que corresponde ao aumento crescente de empresas que investem nessa tecnologia. Nesse sentido, indubitavelmente o trabalhador recebe os reflexos da inovação, o que faz de suma importância as "lentes" jurídico-trabalhistas voltarem seus olhos a esta inovação. A afirmação atemporal do jurista romano Ulpiano faz-se contundente diante de tal "Revolução Nano", em que "onde está a sociedade, lá estará o Direito".

Insta salientar, inclusive, que a inovação se faz alvo de pesquisas que ressaltam o alto índice de dano aos seres vivos. Logo, ainda que na falta de marcos regulatórios, principalmente no que concerne aos solos tupiniquins, uma empresa não pode ser "entendida como um tipo de máquina, orientada exclusivamente para a obtenção do benefício material, mas como um grupo humano, que se propõe a satisfazer necessidades humanas com qualidade", consoante doutrina Engelmann (2019, p. 390).

Logo, garantias e direitos não poderão ser ceifados pela falta de um suporte fático, de uma legislação, diante da produção nano. Dessa forma, as diferentes fontes do Direito necessitam atuar, veementemente, integradas com as "novas orientações" e externas aos "caminhos convencionais" da esfera jurídica.

Nesse sentido, tal problemática será abordada ao longo deste artigo, levando o leitor a compreender que ,diante de tal sociedade laboral - denominada "de risco", devido às inúmeras incógnitas e às adversidades sobrestadas pelo desenvolvimento humano -, há uma necessária metamorfose no Direito ante a "Revolução Nano". Um casulo que se faz pela cocriação de antigos e novos atores para o espetáculo final: a lagarta em uma memorável borboleta trabalhada com as mais honorárias garantias e com a mais perfeita saudabilidade.

Esses novos atores compõem o que Gunther Teubner (2005) denomina de Pluralismo Jurídico, utilizando-se de fontes informais - mas reguladas por aquelas que asseguram a proteção humana - na ausência de fontes estatais; situação que se faz de extrema contundência diante das nanotecnologias e a relação com os direitos dos trabalhadores - considerando a presença desta inovação nas atividades laborais e a falta da atuação legislativa. Tem-se, portanto, a possibilidade de garantir o não retrocesso à dignidade humana do trabalhador.

Assim sendo, as etapas seguintes abordarão os seguintes temas: "O trabalhador em tempos de Revolução Nanotecnológica"; "Uma sociedade de risco e a incongruência na espera do suporte fático de Pontes de Miranda"; "Levantando as travas antirretorno de Prieur: a analogia do direito ambiental para as montanhas do direito do trabalhador"; e "Diante de uma governança policêntrica: a questão do ambiente regulatório pluralista (há direitos e garantias em crise?)".

\footnotetext{
Utilizou-se, aqui, da mesma sinonímia empregada pela doutrinadora Clarissa Tassinari (2019. p. 47). Uma introdução muito se aproxima do pátio central do grande arcabouço de uma obra literária.
} 
O LABOR NANOTECH E A NECESSÁRIA METAMORFOSE JURÍDICA: COMO AS ATUAIS SOCIEDADES DE RISCO PODEM SE VALER DE UM AMBIENTE REGULATÓRIO PLURALISTA PARA A GARANTIA DO NÃO RETROCESSO À DIGNIDADE HUMANA DO TRABALHADOR Wilson Engelmann - Raquel von Hohendorff - Isabelle de Cássia Mendonça

A presente abordagem utilizará o método sistêmico-construtivista, que considera a realidade como uma construção de um observador, analisando todas as peculiaridades implicadas na observação, assim como revisões bibliográficas, por meio de pesquisa de bases que não compõem o Direito tradicional, considerando a transdisciplinaridade do campo de estudo, a fim de observar como as bases jurídicas poderão ser desenvolvidas e comunicadas independente da sua conexão com o Poder Legislativo.

\section{O TRABALHADOR EM TEMPOS DE REVOLUÇÃO NANOTECNOLÓGICA}

A "Revolução Nano" instaurou-se na pós-modernidade sem uma certeza científica sobre a atuação de seus produtos no meio ambiente e sem que a área jurídica tenha construído um marco regulatório específico para estas novas tecnologias. Sua inserção industrial, no entanto, é considerável, e o trabalhador encontra-se à mercê das incógnitas científicas e sem qualquer embasamento legislativo - como se verifica no Brasil.

Antes, todavia, do aprofundamento do tema "nano" e sua relação com o ambiente laboral, faz-se necessário a conceituação do termo nanotecnologia. Trata-se, portanto, de uma ciência que pode ser entendida como "o estudo, a manipulação, e/ou a construção de materiais, substâncias, dispositivos, objetos que estão normalmente na escala nanométrica (1 nanômetro $=10^{-9}$ do metro)" (BRASIL, 2019a).

Insta salientar que a inovação nano demonstra-se extremamente presente. Ainda que não haja uma regulação tradicional formal e legislativo-estatal, mais de 2 mil indústrias, distribuídas por 60 países, utilizam-se de nanotecnologia - uma parcela dessas indústrias, inclusive, está presentes no Brasil. Segundo levantamento de dados realizado na manhã do dia 26 de fevereiro de 2020 na Nanotechnology Products Database (STATNANO, 2019), existem 8.958 produtos que são produzidos por 2.400 empresas espalhadas por 61 países. Os principais setores em que esses produtos são desenvolvidos são: agricultura; automotivo; construção; cosméticos; eletrônicos; aplicações no meio ambiente; alimentos; aparelhos domésticos; medicina; petróleo; impressão em 3D; aplicações em energias renováveis, esportes e fitness e têxteis (STATNANO, 2019).

A atuação desta nova tecnologia é de extrema utilidade no ambiente pós-modernista, principalmente na indústria de vestuário - com roupas impermeáveis - e na indústria dos cosméticos -, tendo em vista a maior eficiência de penetração dos produtos na pele humana.

Há, todavia, pesquisas que demonstram, concomitantemente, que o uso e a presença no ambiente nanotecnológico pode causar danos irreversíveis à saúde humana (BRAND; VAN KESTEREN; OOMEN, 2019). Nesse sentido, cita-se o estudo realizado pelo programa nacional suíço de pesquisa (NATIONALES, 2017) Chancen und Risiken von Nanomaterialien (NFP64), isto é, "Oportunidades e Riscos dos Nanomateriais", lançado em 2010 e concluído em 2017, que realizou mais de 150 publicações, utilizando-se de pesquisas interdisciplinares sobre o tema "nano".

Os estudos da "NFP64" demonstraram que durante o processo de fabricação, quando há nanopartículas livres, assim como durante o uso ou descarte dos produtos com nanomateriais, há um considerável potencial de perigo para os seres vivos. Esses danos, a exemplo, podem ser o acúmulo de partículas nas águas e peixes causando toxicidade ou sendo a causa de doenças neurodegenerativas em seres humanos devido às partículas ultrapassarem a barreira hematoencefálica do sistema nervoso central.

Nesse sentido, este é o cenário a que o trabalhador pós-moderno está exposto. É nessa realidade, extremamente incerta, que os empregados estão a conviver - sem, novamente, nenhum amparo regulamentador "convencional". É pertinente, portanto, a próxima seção, que trará a lume a evidente sociedade de risco e as hipóteses de soluções diante de uma inércia legislativa.

\section{UMA SOCIEDADE DE RISCO E A INCONGRUÊNCIA NA ESPERA DO SUPORTE FÁTICO DE PONTES DE MIRANDA}

Vive-se uma fase em que o desenvolvimento da sociedade encontra-se com "riscos sociais, políticos, econômicos e individuais (que) tendem cada vez mais a escapar das instituições para o controle e a proteção da sociedade industrial" (BECK, 1997, p. 25). Acentua-se o que Bauman (2001) denomina de "caráter líquido dos conceitos clássicos", que é exemplificado no seguinte excerto de Leite e Belchior (2010, p. 293): "tudo que 
O LABOR NANOTECH E A NECESSÁRIA METAMORFOSE JURÍDICA: COMO AS ATUAIS SOCIEDADES DE RISCO PODEM SE VALER DE UM AMBIENTE REGULATÓRIO PLURALISTA PARA A GARANTIA DO NÃO RETROCESSO À DIGNIDADE HUMANA DO TRABALHADOR Wilson Engelmann - Raquel von Hohendorff - Isabelle de Cássia Mendonça

é sólido desvanece no ar. E esta insegurança e incerteza estão se espalhando por todos os ramos de conhecimento, inclusive o Direito".

A nanotecnologia desenvolve-se em diversos setores industriais sem marcos regulatórios específicos... não, somente, em âmbito internacional, mas, também, em solos nacionais, como explanado anteriormente. O nível de insalubridade - e, porque não, periculosidade - está presente nos trabalhadores, sem, nem ao menos, muitos conhecerem o dano que isso pode gerar em seus organismos.

Nesse sentido, embora espera-se uma "regulação tradicional" diante dos riscos inerentes ao mundo nano, faz-se necessário salientar que, diante de uma sociedade de risco, há novas necessidades - características próprias de um desenvolvimento global fluído; isso porque, não somente em questões físico-químicas as nanopartículas e os nanomateriais modificam-se - e o objetivo regulamentador, talvez, torna-se inalcançável ao seu objeto -, mas a volatilidade que há nas mudanças tecnológicas não acompanham o processo legislativo brasileiro, por exemplo, o que torna retrógrado o codex orientador.

Assim sendo, há apenas dois Projetos de Lei no Brasil: Projeto de Lei Complementar $n^{\circ} 23,2019$, buscando alterar a Lei Complementar no 123, de 14 de dezembro de 2006, que dispõe sobre incentivar a pesquisa e desenvolvimento da Nanotecnologia no Brasil (BRASIL, 2019b); e o Projeto de Lei n. 880, de 2019, que trata sobre estímulos ao desenvolvimento científico entre outras providências e institui o Marco Legal da Nanotecnologia e Materiais Avançados (BRASIL, 2019c). Não há, portanto, regulação legislativa sobre o tema nanotecnológico no Brasil.

Nesse sentido, questiona-se: há a necessidade de manter o que o doutrinador Pontes de Miranda (2012, p. 457) lecionava sobre a existência de um suporte fático, isto é, uma previsão no texto da lei (situação abstrata) para se moldar ao caso concreto, e, portanto, o Estado tutelar seus governados?

Claramente a resposta se faz negativa, levantando-se, portanto, a "incongruência pontiana" na "Era nano". O Direito, no caminho do que Bauman alerta, necessita de uma metamorfose, e as lentes do passado não podem servir de guia para os desafios presentes e futuros, para a espera da consequência e, após o conhecimento dela, uma prevenção por meio dos diplomas legais. Isso porque, como antes salientado, os riscos se fazem extremamente preocupantes à saúde humana e ambiental.

Logo, aguardar por uma previsão legal para regulamentar o "labor nano" trata-se de um aceite, muito provável, irreversível à saudabilidade do trabalhador. Nesse sentido, utilizando-se de uma hermenêutica de prevenção, há as demais fontes do Direito, e outras não convencionais - como será explanado posteriormente -, para assegurar a proteção à dignidade humana do trabalhador.

\section{LEVANTANDO AS TRAVAS ANTIRRETORNO DE PRIEUR: A ANALOGIA DO DIREITO AMBIENTAL PARA AS MONTANHAS DO DIREITO DO TRABALHADOR}

Em matéria ambiental, o jurista Michel Prieur (2011) defende, vorazmente, a trava antirretorno nas conquistas ecológico-jurídicas. Compreende que - assim como um alpinista utiliza de instrumentos de segurança para realizar sua escalada com precisão e sem retrocessos - os passos precisos em direção à proteção plena do meio ambiente também necessitam de travas por intermédio das fontes do Direito, para a salvaguarda de um meio ambiente ecologicamente equilibrado.

Tal analogia muito se aproxima do trabalhador e suas garantias. Não se pode retroceder no que o Direito já tenha proporcionado (ou venha a proporcionar) ao ambiente laboral. Logo, há suma necessidade de materiais para impedir a "queda jurídica trabalhista".

Aliás, faz-se necessário mencionar que, inclusive, o "meio ambiente" salientado por Prieur - e exarado na Constituição Federal brasileira, fundamentalmente, em seu artigo 225 -, está além da constituição biota, isto é, além do solo, da água, do ar, da fauna e da flora - além do denominado "meio ambiente natural". Há, nas diversas facetas de "ambiente", que necessitam de tutela, a inclusão do meio ambiente do trabalho (FIGUEIREDO, 2007).

Quanto ao não retrocesso, o artigo 70 da Constituição Federal expressa "natureza progressiva" (MELO, 2010, p. 67) referente à questão laboral: "São direitos dos trabalhadores urbanos e rurais, além de outros que 
O LABOR NANOTECH E A NECESSÁRIA METAMORFOSE JURÍDICA: COMO AS ATUAIS SOCIEDADES DE RISCO PODEM SE VALER DE UM AMBIENTE REGULATÓRIO PLURALISTA PARA A GARANTIA DO NÃO RETROCESSO À DIGNIDADE HUMANA DO TRABALHADOR Wilson Engelmann - Raquel von Hohendorff - Isabelle de Cássia Mendonça

visem à melhoria de sua condição social." Esses direitos, exemplificativos proporcionam a listagem de direitos sociais aos obreiros - resguardando os já alcançados e aqueles que, ainda, possam ser conquistados.

Nesse sentido, as normas hão de "traduzir somente confirmações ou avanços civilizatórios no plano interno a que se dirigem, não podendo prevalecer caso signifiquem diminuição de padrão protetivo em contraponto com as regras internas" (DELGADO, 2017, p. 65).

Tal diminuição de padrão protetivo poderá ser, inclusive, a plena inércia, omissão no tratamento com o trabalhador.

Nesse contexto, voltando-se ao lume da presente pesquisa, as observações de não retrocesso são indispensáveis no contexto nanotecnológico para as atuais e futuras gerações laborativas. Isso porque a produção e manipulação "nano" apresenta-se sem amparo regulamentador, consoante já aludido em raciocínios anteriores.

Ademais, a incognoscibilidade em relação às consequências e aos danos nos trabalhadores (assim como, em uma visão macro, ao próprio ecossistema), faz-se um imperativo para a sustentação de travas ao retrocesso de garantias e de direitos dos trabalhadores expostos a "nanoambientes".

Assim sendo, referente à visão do comando internacional, a Organização Internacional do Trabalhador (OIT), em seu artigo 4으, na Convenção no 155 (BRASIL, 1994), ratificada pelo Brasil, determina a adoção de uma política nacional coerente em matéria de segurança e saúde dos trabalhadores e o meio ambiente de trabalho.

Utilizando-se, ainda, do arcabouço raciocínio de Prieur como viés para os lindes trabalhistas, pode-se afirmar que, em matéria de Direito do Trabalho, também "há sólidos fundamentos éticos, políticos e constitucionais, legais e jurisprudenciais no Brasil e em outras Nações a garantir o não retrocesso das conquistas jurídicas, na esteira do que também se observa no terreno dos direitos humanos" (PRIEUR, 2011. p. 25).

Nesse sentido, em plena harmonia com a dignidade humana, posto que se está a tratar da saudabilidade do trabalhador, fortalecer a não regressão nas salvaguardas trabalhistas é estar a proteger o labor digno. Insta salientar que "nos termos da Declaração Universal dos Direitos do Homem, a finalidade desses direitos é a de favorecer o progresso social e instaurar melhores condições de vida". Ademais, a não regressão prevista nos direitos humanos "é mais que implícita, ela é ética, prática e quase judiciária" (PRIEUR, 2011. p. 26).

Embora não haja o suporte fático para embasar as causas envolvendo trabalhadores e nanotecnologias, consoante salientado nos raciocínios anteriores, não se faz palatável o aceite, indiscriminado, de uma inovação é incógnita, inclusive, para cientistas. Nesses termos, a seguir proceder-se-á à análise de um ambiente plural regulatório, valendo-se do caminho "convencional" das fontes jurídicas, assim como do suporte de "fontes particulares", sem dirimir e colocar em perigo o papel do Leviatã no Contrato Social (HOBBES, 2006).

\section{DIANTE DE UMA GOVERNANÇA POLICÊNTRICA: A QUESTÃO DO AMBIENTE REGULATÓRIO PLURALISTA (HÁ DIREITOS E GARANTIAS EM CRISE?)}

Cogitar influências externas ao sistema do Direito pode levar à conclusão do enfraquecimento, substancial, do padrão legislativo e das demais fontes do ordenamento, influenciando, inclusive, na dirimição de direitos e de garantias fundamentais e humanos. Faz-se necessário, todavia, compreender a ideia de policentricidade do direito e até que ponto este estandarte é viável em nossa realidade.

O Pluralismo Jurídico compreende "a multiplicidade de diversos processos comunicativos, que observam a atuação social mediante um código lícito/ilícito" (TEUBNER, 2005, p. 25), e visa a

[...] concentrar a sua atenção em processos "espontâneos" de formação do direito que compõem uma nova espécie e se desenvolveram - independentemente de um direito instituído pelos Estados individuais ou no plano interestatal - em diversas áreas da sociedade mundial (TEUBNER, 2005, p. 11).

Gunther Teubner apresenta tal hipótese, que se faz necessária diante dos novos desafios que se apresentam em uma sociedade de risco. Há a necessidade de "outros atores de produção do jurídico e Fontes do Direito que até então sempre estiveram à sombra do texto da lei, mormente na estrutura normativista do Direito, consolidada a partir de Hans Kelsen" (ENGELMANN, 2012, p. 312) e diante da realidade nanotecnológica. 
O LABOR NANOTECH E A NECESSÁRIA METAMORFOSE JURÍDICA: COMO AS ATUAIS SOCIEDADES DE RISCO PODEM SE VALER DE UM AMBIENTE REGULATÓRIO PLURALISTA PARA A GARANTIA DO NÃO RETROCESSO À DIGNIDADE HUMANA DO TRABALHADOR Wilson Engelmann - Raquel von Hohendorff - Isabelle de Cássia Mendonça

Estes atores não são normas avessas ao Direito. O pluralismo, aqui defendido, trata-se da utilização de fontes informais que se manifestam sob o baluarte das fontes formais do ordenamento, assegurando o não rompimento da proteção humana; em especial, sob o crivo do princípio do não retrocesso - tematizado no presente artigo.

Para esta seguridade, a doutrina denomina autorregulação regulada, isto é, a "intervenção dos entes privados no processo de regulação, de forma subordinada aos fins de interesse público estabelecidos pelo Estado" (BREIER; CARRIL, 2013)³. Essas fontes informais podem se tratar de organizações nacionais e internacionais, agências regulatórias e ONGs.

Em especial, para o caso em comento, em relação às nanotecnologias e o ambiente laboral, cita-se os "órgãos privados que estabelecem padrões normativos, mecanismos e instrumentos que são adotados por um grande número de países, tal como as normas ISO" (SILVA; SANTOS, 2016, p. 362).

Nesse sentido, em especial destaca-se o Comitê 229 da Organização Internacional de Padronização, que "atua na elaboração de normas técnicas para auxiliar no processo de harmonização e regulação das nanotecnologias" (BRASIL, 2019a). Tais normas, portanto, viabilizariam que os empregadores atuassem de maneira a preservar a dignidade humana dos seus colaboradores, mesmo que aqueles utilizem, em suas empresas, uma inovação que não está, ainda, regulamentada sob o âmbito do padrão legislativo.

Ademais, é importante salientar a observação de Engelmann e Martins (2017, p. 92):

Há que se observar que se trata de normas (ISO) de adoção voluntária, todavia, de reconhecimento internacional no âmbito de organizações privadas e instituições ou órgãos de governos, que buscam demonstrar boas práticas de gestão e tornarem-se mais competitivos no mercado interno e externo. Assim, não são postas pelos Estados, mas são por eles reconhecidas através das instituições ou órgãos aos quais foram outorgadas competências, no caso brasileiro, a ABNT. De sorte que é viável considerar que integram o ordenamento jurídico, ainda que possuam status normativo regulatório técnico.

Pode-se questionar, todavia, se, ao possibilitar-se a atuação de particulares em uma esfera, propriamente de atuação estatal, não se estaria se dando um aval à supressão de direitos e garantias, considerando que os próprios particulares estariam coordenando seu modo de atuação. Insta, entretanto, observar tal raciocínio:

[...] Ao adotar uma abordagem pluralista e descentralizada da regulação, que utiliza uma série de técnicas regulatórias [...] os atores não estatais podem contribuir de diversas maneiras para esses desafios especiais. [...] A confiança e a desconfiança do público na regulação do risco são cruciais para garantir a viabilidade da estrutura de controle, até porque o pluralismo regulatório frequentemente prevê a cooperação entre o Estado e a indústria. No entanto, o envolvimento de atores não-estatais, incluindo a indústria, é importante se o marco regulatório não for para impedir o desenvolvimento tecnológico ou expor o público a riscos inaceitáveis ${ }^{4}$ (ABBOT, 2012, p. 392, 242).

Ademais, há consideráveis benefícios quando atores privados e públicos estão em harmonia, inclusive destacando-se um controle de qualidade rigoroso na atuação de empresas que já se valem desse mecanismo de regulamentação - como é contundente tal observação em âmbito internacional5:

[...] Na maior parte das economias da União Europeia, houve uma mudança completa dos mecanismos de construção da regulação, refletindo o desejo de melhorar a qualidade da regulação, reduzindo a carga administrativa para os requerentes e apoiando um maior enfoque na mitigação dos riscos [...] A colaboração público-privada na construção da regulação tem mostrado resultados positivos, incluindo uma melhor conformidade com os regulamentos, um controle de qualidade mais rigoroso durante todo o ciclo de vida do projeto

\footnotetext{
3 Mais informações: Engelmann (2019, p. 381) e Ogus (2011).

4 Tradução Engelmann (2019, p. 384).

5 Nesse sentido, além da contribuição das normas ISO, salienta-se a Agência Europeia para a Saúde e Segurança do Trabalho (OSHA), o Instituto Nacional de Saúde e Segurança Ocupacional dos Estados Unidos (NIOSH) e o Institute for Health and Consumer Protection - European Comission (GÓES; ENGLEMANN, 2015, p. 207).
} 
O LABOR NANOTECH E A NECESSÁRIA METAMORFOSE JURÍDICA: COMO AS ATUAIS SOCIEDADES DE RISCO PODEM SE VALER DE UM AMBIENTE REGULATÓRIO PLURALISTA PARA A GARANTIA DO NÃO RETROCESSO À DIGNIDADE HUMANA DO TRABALHADOR Wilson Engelmann - Raquel von Hohendorff - Isabelle de Cássia Mendonça

e melhor eficiência de processamento. [...] Um sólido regulamento de construção pode salvar vidas humanas, melhorar a saúde e a segurança e apoiar um setor e uma economia prósperos e sustentáveis ${ }^{6}$ (THE WORLD BANK, 2018. p. 48-49).

Pode-se estender ao raciocínio a clara "governança" que se apresenta para a organização e para a gestão da sociedade, uma vez que somente o comando estatal não atenderá às demandas complexas nos novos desafios pós-modernistas. Nesse sentido, uma rede de novos atores se faz presente e necessária (AVEN; RENN, 2019 , p. 3). Logo, a atuação colaborativa público-privada possibilita uma atuação categórica para a proteção humana. Nisso se vale, portanto, a necessária metamorfose no Direito, título da presente obra. O casulo que prepara uma nova perspectiva do ordenamento. Jamais insegura, jamais regressiva, mas o necessário processo da antiga lagarta para a ascensão da mais nova borboleta, a "governança policêntrica".

\section{CONSIDERAÇÕES FINAIS}

O presente artigo tratou da relação laboral com o atual cenário nanotecnológico e os desafios que tal realidade proporciona ao Direito do trabalho. Em especial, ressaltou-se a falta de marcos regulatórios específicos em relação à "revolução nano" e, portanto, a iminência à mácula a direitos fundamentais e humanos dos trabalhadores, sendo necessário, portanto, o uso de outras fontes para a tutela daqueles.

Nesse sentido, compreendeu-se que o aparato protetor que se pode utilizar, considerando a sociedade de risco, trata-se da harmonização de fontes, isto é, a atuação de atores formais e informais (o pluralismo jurídico, objeto de estudo do autor Gunther Teubner) na elaboração de regras de atuação e manipulação de nanoparticulas no ambiente laboral.

Buscou-se, desse modo, evidenciar quão importante e necessário se faz a instituição do pluralismo jurídico, que pode ser representado pela autorregulação regulada.

Ainda que incerto o verdadeiro efeito da nanotecnologia - e a inércia legislativa -, as normas, aqui salientadas, estão sob o júbilo do princípio do não retrocesso, que exige respeito aos direitos e às garantias que estão e que serão assegurados aos trabalhadores, sem a possibilidade de retroceder nas conquistas do Direito brasileiro.

Ademais, os raciocínios, aqui depreendidos, não são meras discussões literárias, restritas ao mundo das ideias. Conforme evidenciado, os Estados tendem a utilizar novas formas de normatização, sem a atuação "meramente estatal", conforme o excerto de Abbot (2012, p. 242): "um controle de qualidade mais rigoroso durante todo o ciclo de vida do projeto e melhor eficiência de processamento". Os dados vêm a demonstrar e assegurar, portanto, a possibilidade de convivência de "regramentos particulares" - como a própria norma ISO - com a Magna Carta e demais fontes do Direito.

Nesse liame, com base nos raciocínios aqui depreendidos, salienta-se a urgência na atuação de atores privados e de entes públicos para assegurar a dignidade laboral em ambientes nano. É imprescindível compreender que, adaptando a frase de Rubem Alves, "não haverá borboletas se o Direito não passar por longas (e audíveis) metamorfoses".

Assim sendo, conforme salienta Hohendorff (2019, p. 293), considerando que se tratam de "riscos abstratos, invisíveis, globais, transtemporais, retardados e irreversíveis, na medida em que (as nanotecnologias) evidenciam enorme potencial de risco", uma vez que diz respeito a "uma nova ciência, [...] nunca antes estudad(a)", o Direito deverá compor sua devida metamorfose, uma nova reestruturação consequente do caráter líquido dos conceitos clássicos, de uma "sociedade nano" de risco, sem qualquer amparo legislativo. Logo, um ambiente regulatório pluralista proporcionará o avanço à dignidade humana do trabalhador, esta que se trata "do sustentáculo de qualquer trabalho humano" (DELGADO, 2006, p. 207).

6 Tradução Engelmann (2019, p. 374). 
O LABOR NANOTECH E A NECESSÁRIA METAMORFOSE JURÍDICA: COMO AS ATUAIS SOCIEDADES DE RISCO PODEM SE VALER DE UM AMBIENTE REGULATÓRIO PLURALISTA PARA A GARANTIA DO NÃO RETROCESSO À DIGNIDADE HUMANA DO TRABALHADOR Wilson Engelmann - Raquel von Hohendorff - Isabelle de Cássia Mendonça

\section{REFERÊNCIAS}

ABBOT, C. Non-state Actors and the Challenges of Regulating New Technology. Journal of Law and Society, 39, 3, p. 329-358, Sep. 2012.

ALVES, Rubem. Entre a Ciência e a Sapiência: o dilema da educação. 21. Ed. São Paulo: Edições Loyola, 1999. p. 24.

AVEN, T.; RENN, O. Some foundational issues related to risk governance and different types of risks. Journal of Risk Research, p. 1-14, 2019.

BAUMAN, Z. Modernidade líquida. Rio de Janeiro: Jorge Zahar, 2001.

BECK, U. A reinvenção da política: rumo a uma teoria da modernização reflexiva. In: BECK, U.; GIDDENS, A.; LASH, S. Modernização reflexiva: política, tradição e estética na ordem social moderna. São Paulo: Unesp, 1997.

BRAND, W.; VAN KESTEREN, P. C. E.; OOMEN, A. G. Potential health risks of nanomaterials in food: a methodology to identify signals and prioritise risks [Mogelijke gezondheidsrisico's van nanomaterialen in voedsel: een methode om risico's te signaleren en te prioriteren]. RIVM letter report 2019-0191. Disponível em: https://www.rivm.nl/bibliotheek/rapporten/2019-0191. pdf. Acesso em: 30 jan. 2020

BRASIL. Decreto no 1.254, de 29 de setembro de 1994. Promulga a Convenção número 155, da Organização Internacional do Trabalho, sobre Segurança e Saúde dos Trabalhadores e o Meio Ambiente de Trabalho, concluída em Genebra, em 22 de junho de 1981. Disponível em: http://www.planalto.gov.br/ccivil_03/decreto/1990-1994/d1254.htm Acesso em: 30 jan. 2020.

BRASIL. Ministério da Ciência, Tecnologia, Inovações e Comunicações. Benefícios e riscos das nanotecnologias. Centro Nacional de Pesquisa em Energia e Materiais (CNPEM). 2019a. Disponível em: https://Innano.cnpem.br/wp-content/uploads/2019/10/ SEPARATA-CNPEM-02_Benef\%C3\%ADcios-e-riscos-das-nanotecnologias.pdf. Acesso em: 20 jan. 2020.

BRASIL. Projeto de Lei Complementar no 23, 2019. Altera a Lei Complementar no 123, de 14 de dezembro de 2006 a fim de incentivar a pesquisa e desenvolvimento da Nanotecnologia no Brasil. 2019b. Disponível em: https://www25.senado.leg.br/ web/atividade/materias/-/materia/135203. Acesso em: 26 fev. 2020.

BRASIL Projeto de Lei $n$ o 880, 2019. Institui o Marco Legal da Nanotecnologia e Materiais Avançados; dispõe sobre estímulos ao desenvolvimento científico, à pesquisa, à capacitação científica e tecnológica e à inovação nanotecnológica; altera as Leis no 10.973, de 2 de dezembro de 2004, e no 8.666, de 21 de junho de 1993; e dá outras providências. 2019c. Disponível em: https://www25.senado.leg.br/web/atividade/materias/-/materia/135353. Acesso em: 20 jan. 2020.

BREIER, R.; CARRIL, R. Autorregulação impacta direito penal empresarial. 2013. Disponível em: https://www.conjur.com.br/ 2013-set-28/autorregulacao-produz-impactos-direito-penal-empresarial. Acesso em: 20 fev. 2020.

DELGADO, G. N. Direito fundamental ao trabalho digno. São Paulo: LTr, 2006.

DELGADO, M. G. Curso de direito do trabalho. 16. ed. São Paulo: LTr, 2017.

ENGELMANN, W. Estruturando um ambiente regulatório pluralístico a partir da gestão dos riscos nanotecnológicos e da responsabilidade empresarial. In: BRAGATO, Fernanda Frizzo; STRECK, L. L.; ROCHA, L. S. Constituição, sistemas sociais e hermenêutica: anuário do Programa de Pós-Graduação em Direito da Unisinos: Mestrado e Doutorado, n. 15. São Leopoldo: Karywa; Unisinos, 2019.

ENGELMANN, W. O diálogo entre as fontes do direito e a gestão do risco empresarial gerado pelas nanotecnologias: construindo as bases à juridicização do risco. In: STRECK, L. L.; ROCHA, L. S.; ENGELMANN, W. Constituição, sistemas sociais e hermenêutica: anuário do Programa de Pós-Graduação em Direito da Unisinos: Mestrado e Doutorado, n. 9. Porto Alegre: Livraria do Advogado; São Leopoldo: Ed. Unisinos, 2012.

ENGELMANN, W.; MARTINS, P. S. A ISO, suas normas e estruturação: possíveis interfaces regulatórias. In: ENGELMANN, W.; MARTINS, P. S. As Normas ISO e as nanotecnologias: entre a autorregulação e o pluralismo jurídico. São Leopoldo: Karywa, 2017.

FIGUEIREDO, J. G. P. Direito ambiental e a saúde dos trabalhadores. 2. ed. São Paulo: LTr, 2007.

GLOBAL Nanotechnology Market (by Component and Applications). Funding \& Investment, Patent Analysis and 27 Companies Profile \& Recent Developments - Forecast to 2024. iGATE Research, Apr. 2018.

GÓES, M. C.; ENGLEMANN, W. Direito das nanotecnologias e no meio ambiente do trabalho. Porto Alegre: Livraria do Advogado Editora, 2015.

HOBBES, T. Leviatã. São Paulo: Ed. Martin Claret, 2006.

HOHENDORFF, R. As categorias de risco e perigo na teoria de Niklas Luhmann: caracterizando risco e perigo de modo a posicionar o direito em um cenário de complexa distinção frente aos desafios das novas tecnologias. In: BRAGATO, Fernanda Frizzo; STRECK, L. L.; ROCHA, L. S. Constituição, sistemas sociais e hermenêutica: anuário do Programa de Pós-Graduação em Direito da Unisinos: Mestrado e Doutorado, n. 15. São Leopoldo: Karywa; Unisinos, 2019. 


\section{Direito自 Debate}

O LABOR NANOTECH E A NECESSÁRIA METAMORFOSE JURÍDICA: COMO AS ATUAIS SOCIEDADES DE RISCO PODEM SE VALER DE UM AMBIENTE REGULATÓRIO PLURALISTA PARA A GARANTIA DO NÃO RETROCESSO À DIGNIDADE HUMANA DO TRABALHADOR Wilson Engelmann - Raquel von Hohendorff-Isabelle de Cássia Mendonça

LEITE, J. R. M.; BELCHIOR, G. P. N. B. O Estado de Direito Ambiental e a particularidade de uma hermenêutica jurídica. Seqüência, n. 60, p. 291-318, jul. 2010.

MELO, G. M. A vedação ao retrocesso e o direito do trabalho. Rev. Trib. Reg. Trab. 3a Reg., Belo Horizonte, v. 52, n. 82, p. 65-74, jul./dez. 2010.

NATIONALES, F. NFP 64. Chancen und Risiken von Nanomaterialien: Ergebnisse, Erkenntnisse und Perspektiven - Schlussbroschüre. Schweizerischer Nationalfonds zur Förderung der wissenschaftlichen Forschung (SNF). 2017. Disponível em: http:// www.nfp64.ch/SiteCollectionDocuments/Schlussbroschuere_NFP64_D.pdf. Acesso em: 10 nov. 2019.

OGUS, Anthony. Self-regulation. In: PARISI, F. Production of Legal Rules. Encyclopedia of Law and Economics. 2. ed. [S.I.]: Edward Elgar, v. 7, 2011.

PONTES DE MIRANDA, F. C. Tratado de direito privado. Tomo I. São Paulo: Revista dos Tribunais, 2012.

PRIEUR, M. O princípio da proibição de retrocesso ambiental. In: BRASIL. Congresso Nacional. Senado Federal. Comissão de Meio Ambiente, Defesa do Consumidor e Fiscalização e Controle. O princípio da proibição de retrocesso ambiental. Brasília: Senado Federal, 2011. p. 11-56.

SILVA, Alice Rocha da; SANTOS, Ruth Maria Pereira dos. As diretivas europeias como norma reguladora do direito administrativo global. Revista de Direito Internacional, Brasília, v. 13, n. 3, p. 355-373, 2016.

STATNANO. Nanotechnology Products Database (NPD). 2019. Disponível em: http://product.statnano.com/. Acesso em: 28 fev. 2020.

TASSINARI, C. A relação direito e política em tempos de protagonismo judicial: elementos introdutórios sobre a dinâmica entre os três poderes. In: BRAGATO, F. F.; STRECK, L. L.; ROCHA, L. S. Constituição, sistemas sociais e hermenêutica: anuário do Programa de Pós-Graduação em Direito da Unisinos: Mestrado e Doutorado, n. 15. São Leopoldo: Karywa; Unisinos, 2019.

TEUBNER, G. Direito, sistema e policontexturalidade. Piracicaba: Ed. Unimep, 2005.

THE WORLD BANK. Doing Business 2018: reforming to create jobs. Washington: International Bank for Reconstruction and Development/The World Bank, 2018. p. 48-49. 